\title{
AVERSIVE STIMULUS DIFFERENTIALLY TRIGGERS SUBSECOND DOPAMINE RELEASE IN REWARD REGIONS
}

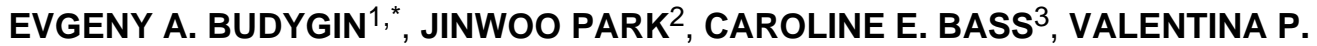 \\ GRINEVICH $^{1}$, KEITH D. BONIN ${ }^{4}$, and R. MARK WIGHTMAN ${ }^{2}$ \\ ${ }^{1}$ Medical Center Boulevard, Department of Physiology and Pharmacology, Wake Forest \\ University School of Medicine, Winston-Salem, North Carolina 27157, USA \\ ${ }^{2}$ Department of Chemistry, University of North Carolina at Chapel Hill, Chapel Hill, North Carolina \\ 27599 \\ ${ }^{3}$ Department of Pharmacology and Toxicology, State University of New York at Buffalo, Buffalo, \\ NY 14214 \\ ${ }^{4}$ Olin Physical Laboratory, Department of Physics, Wake Forest University, Winston-Salem, North \\ Carolina 27109
}

\begin{abstract}
Aversive stimuli have a powerful impact on behavior and are considered to be the opposite valence of pleasure. Recent studies have determined some populations of VTA dopaminergic neurons are activated by several types of aversive stimuli while other distinct populations are either inhibited or unresponsive. However, it is not clear where these aversion responsive neurons project, and whether alterations in their activity translate into dopamine release in the terminal field. Here we show unequivocally that the neurochemical and anatomical substrates responsible for the perception and processing of pleasurable stimuli within the striatum are also activated by tail pinch, a classical painful and aversive stimulus. Dopamine release is triggered in the dorsal striatum and nucleus accumbens (NAc) core by tail pinch and is time locked to the duration of the stimulus, indicating that the dorsal striatum and NAc core are neural substrates, which are involved in the perception of aversive stimuli. However, dopamine is released in the NAc shell only when tail pinch is removed, indicating that the alleviation of aversive condition could be perceived as a rewarding event.
\end{abstract}

\section{Keywords}

voltammetry; tail pinch; nucleus accumbens

Dopamine signaling in the nucleus accumbens (NAc) is involved in the integration of sensory information and the initiation of the subsequent behavioral responses to diverse stimuli (Leknes and Tracey, 2008). The perception and behavioral consequences of rewarding and aversive stimuli are extremely different, and the underlying neural substrates mediating these opposing phenomena are unclear. Increased subsecond dopamine release in

\footnotetext{
(C) 2011 IBRO. Published by Elsevier Ltd. All rights reserved.

"Correspondence should be addressed to: Evgeny Budygin, Ph.D., ebudygin@wfubmc.edu, Tel: (336) 716-8530, Fax: (336) 716-8501. Publisher's Disclaimer: This is a PDF file of an unedited manuscript that has been accepted for publication. As a service to our customers we are providing this early version of the manuscript. The manuscript will undergo copyediting, typesetting, and review of the resulting proof before it is published in its final citable form. Please note that during the production process errors may be discovered which could affect the content, and all legal disclaimers that apply to the journal pertain.
} 
this brain region has been demonstrated with the presentation, seeking and anticipation of reward (Phillips et al., 2003; Day et al., 2007; Roitman et al., 2008) as well as learning of reward-related information (Day et al., 2007; Owesson-White et al., 2008; Roitman et al., 2008). According to the reward coding hypothesis (Schultz, 1998; Montague et al., 2004a; Ungless, 2004; Ungless et al., 2004) mesolimbic dopamine neurons are inhibited or unresponsive to aversive stimuli, and increased dopamine release only occurs with rewardrelated stimuli. For example, the inhibition of dopamine release in rat NAc was observed during a $4 \mathrm{~s}$ intra-oral exposure to quinine in a taste aversion model (Roitman et al., 2008). Others have suggested an alternative hypothesis in which increases in phasic dopamine activity can be initiated by any salient stimuli regardless of valence, including aversive stimuli (Redgrave et al., 1999; Redgrave et al., 2008; Anstrom et al., 2009). In support of this claim, it has been shown that significant increases in subsecond dopamine transmission occur in the NAc of rats under the aversive condition of social defeat stress (Anstrom et al., 2009).

Recently, an electrophysiology study discovered regional differences in dopamine neuronal firing within the VTA of anesthetized rats exposed to brief (4 s) footshock (Brischoux et al., 2009). They found that footshock inhibited dopamine neurons in the dorsal VTA, while those in the ventral VTA were phasically excited. The study, performed on behaving mice showed that the majority of the VTA dopamine neurons exhibit decreased activity, while a small group of dopaminergic-like neurons can be activated by fearful events (Wang and Tsien, 2011). Another study in mice reported nearly equivalent proportions of dopamine neurons activated, inhibited or unaltered by $5 \mathrm{~s}$ tail pinch (Zweifel et al., 2011). Therefore, electrophysiological studies clearly demonstrate that the activity of a subset of dopamine neurons in the VTA and substantia nigra can increase in response to aversive stimuli (Zweifel et al., 2011; Brischoux et al., 2009; Matsumoto and Hikosaka, 2009; Wang and Tsien, 2011). However, it is still not known how prevalent these aversion-excitable dopaminergic neurons are, and whether their increased activity translates into dopamine release in the terminal fields. Notably, changes in the activity of dopaminergic neurons in the VTA does not necessarily produce a proportional response in dopamine release in the terminal regions, since terminal mechanisms and conditions may also shape the temporal profile of extracellular dopamine (Montague et al., 2004b; Wightman et al., 2007; Lammel et al., 2008). To address the fundamental question of whether and how dopamine neurotransmission within the NAc encodes aversive stimuli, we have assessed dopamine dynamics in real-time in response to the classical aversive stimulus, a $3 \mathrm{~s}$ tail pinch.

\section{EXPERIMENTAL PROCEDURES}

\section{Fast-scan cyclic voltammetry (FSCV)}

Naïve male Sprague-Dawley rats weighing approximately $350 \mathrm{~g}$ were housed with ad libitum food and water in a 12/12 hr light/dark cycle. All procedures were approved by the Wake Forest University and University of North Carolina Animal Care and Use Committees. Experiments were performed on anesthetized animals. Naïve rats were anesthetized with urethane $(1.5 \mathrm{~g} / \mathrm{kg}$, i.p. $)$ and placed in a stereotaxic frame. A carbon fiber electrode (50-100 $\mu \mathrm{m}$ exposed tip length, $7 \mu \mathrm{m}$ diameter, Goodfellow, Oakdale, PA, USA) was positioned in the NAc core (AP +1.3, L+1.3, V $-6.3--7.2 \mathrm{~mm}$ from bregma) or NAc shell $(\mathrm{AP}+1.8, \mathrm{~L}+0.9, \mathrm{~V}-6.8--7.2 \mathrm{~mm})$ or dorsal striatum $(\mathrm{AP}+1.3, \mathrm{~L}+1.3, \mathrm{~V}-4.5-$ $-5.0 \mathrm{~mm}$ ) (3 separate groups of rats, $\mathrm{n}=5-6$ per group). $\mathrm{An} \mathrm{Ag} / \mathrm{AgCl}$ reference electrode was inserted in the contralateral hemisphere. The reference and carbon fiber electrodes were connected to a voltammetric amplifier and voltammetric recordings were made at the carbon fiber electrode by applying a triangular waveform $(-0.4$ to $+1.3 \mathrm{~V}$ versus $\mathrm{Ag} / \mathrm{AgCl}, 400 \mathrm{~V} /$ $\mathrm{s})$. 
To avoid tissue damage and electrical noise artifacts during voltammetric recordings, the tail pinch was performed with soft rubber gloves. The tail of the rat was placed between the thumb and the index finger and pinched for a period of $3 \mathrm{~s}$. The pinch was administered 1 $\mathrm{cm}$ from posterior tip of tail with maximal pressure $(\mathrm{P})$ of $3.12 \pm 0.62 \mathrm{MPa}$. $\mathrm{P}$ was calculated by measuring the contact area between the fingers and the tail, and by a measurement of the applied force using a Pasco CI-6537 Force Sensor. This test was repeated 4 times with intervals of 2-3 minutes between each pinch. No reactions such as ear or whisker twitches were observed during this procedure. At the end of experiment, GBR 12909 (15 mg/kg, i.p.), a selective dopamine transporter inhibitor, was injected for the pharmacological confirmation of the pinch-induced electrochemical signal.

Data were digitized and stored on a computer. Carbon fiber electrodes were calibrated in vitro with known concentrations of dopamine $(0.2,0.5$ and $1.0 \mu \mathrm{M})$. Calibrations were done in duplicate and the average value for the current at the peak oxidation potential was used to normalize in vivo signals to dopamine concentration. When the carbon fiber electrode was used to lesion the brain for placement verification, an averaged post calibration was employed to calculate dopamine concentration (Park et al., 2010).

\section{Chemicals and Drugs}

All chemicals and drugs were reagent-quality and used without additional purification. Drugs were obtained from Sigma-Aldrich (St. Louis, MO, USA). In vitro dopamine calibration of microelectrodes was performed in a tris buffer solution at $\mathrm{pH} 7.4$ containing $15 \mathrm{mM}$ Tris, $140 \mathrm{mM} \mathrm{NaCl}, 3.25 \mathrm{mM} \mathrm{KCl}, 1.2 \mathrm{mM} \mathrm{CaCl}_{2}, 1.25 \mathrm{mM} \mathrm{NaH}_{2} \mathrm{PO}_{4}, 1.2 \mathrm{mM}$ $\mathrm{MgCl}_{2}$ and $2.0 \mathrm{mM} \mathrm{Na}_{2} \mathrm{SO}_{4}$ in double distilled water (Mega Pure System, Corning Glasswork, Corning, NY, USA). GBR 12909-HCl was dissolved in a small volume of distilled water and diluted with saline. Injected volumes were $1 \mathrm{~mL} / \mathrm{kg}$ and were given i.p.

\section{Histological Verification of Electrode Placement}

Electrode placements were verified stereotaxically as described previously (Anstrom et al., 2009; Park et al., 2010). A lesion was made at the recording site by applying constant current ( $20 \mu \mathrm{A}$ for $10 \mathrm{~s}$ ) to the tungsten or carbon fiber electrodes. Brains were removed from the skulls and stored in $10 \%$ formaldehyde for at least 3 days, then they were coronally sectioned into $40-50 \mu \mathrm{m}$ thick slices with a cryostat. The sections mounted on slides were stained with $0.2 \%$ thionine, and coverslipped before viewing under a light microscope. Figure 5 demonstrates anatomical distribution of carbon fiber electrode placements in the NAc shell, NAc core and dorsal striatum. Coronal diagrams show electrode tip locations for 18 rats. Coordinates were taken from a stereotaxic atlas.

\section{Statistical Analysis}

Data were analyzed in GraphPad Prism (GraphPad Software, San Diego, CA). Paired t-test and one- and two-way ANOVAs with a Bonferroni post tests were used to determine statistical significance. The data are presented as mean \pm SEM and the criterion of significance was set at $\mathrm{p}<0.05$.

\section{RESULTS}

A tail pinch induced a significant increase in extracellular dopamine concentration in the rat striatum (Fig. 1). However, significant differences in tail pinch-evoked dopamine release were revealed between striatal subregions (one-way ANOVA; $F[2,15]=10.75, P<0.005$ ). Specifically, dopamine release in the dorsal striatum was significantly less than in the NAc core and shell (Bonferroni's Multiple Comparison Test, $P<0.01, \mathrm{n}=6$ per group, Fig. 2A). No difference was observed between subregions of NAc $(P>0.05)$. Importantly, there was a 
significant difference in the onset of pinch-induced dopamine release between NAc core and shell (one-way ANOVA; $F[2,15]=66.89, P<0.0001$ ). Dopamine release in the NAc shell was notably delayed in comparison with that in the dorsal striatum and NAc core (Bonferroni's Multiple Comparison Test, $P<0.001, \mathrm{n}=6$ per group). At the same time, dopamine release in the NAc core and dorsal striatum was closely coupled to the stimulus (Fig. 2B). Importantly, tail pinch induced a stable response in all tested striatal subregions (Fig. 3). There was no significant difference in the amplitude of dopamine efflux after four sequential tail pinches (two-way ANOVA; $F[3,48]=0.1909, P>0.05, \mathrm{n}=5$ per group). Dopamine responses, which were detected in the dorsal striatum, NA core and shell following the first pinch were $21.3 \pm 2.7,36.4 \pm 10.1$ and $48.9 \pm 12.3 \mathrm{nM}$, respectively (Fig. $3)$. We also assessed dopamine release changes in the NAc core in response to a foot pinch. The amplitude of dopamine efflux, which was reached during the $3 \mathrm{~s}$ stimuli, did not significantly differ between foot and tail pinches $(32.4 \pm 4.2 \mathrm{nM}$ versus $42.4 \pm 4.5 \mathrm{nM}$, respectively; Bonferroni's Multiple Comparison Test, $P>0.05, \mathrm{n}=5$ per group). Pinchinduced dopamine release in the same region was also compared with the release evoked by 3 s electrical $(30 \mathrm{~Hz}, 300 \mu \mathrm{A})$ stimulation of VTA (one-way ANOVA; $F[2,12]=27.64$, $P<0.0001)$. The increase in accumbal dopamine following an electrical stimulation was approximately 20 times higher compared to that induced by foot and tail pinches (Bonferroni's Multiple Comparison Test, $P<0.001, \mathrm{n}=5$ per group).

Figure 4 shows tail pinch-induced dopamine changes detected by FSCV in the rat NAc shell before (left) and 30 min after (right) administration of GBR 12909, a selective dopamine transporter inhibitor. Representative background-subtracted voltammograms obtained at the end of the stimulus showed oxidation and reduction peak potentials $(\sim+0.6 \mathrm{~V}$ and $\sim-0.2 \mathrm{~V}$, respectively) that are consistent with dopamine characteristics. Representative concentration-time plots of stimulus evoked signals exhibit marked decline in the uptake of detected catecholamine following GBR 12909 administration (the return of signal to baseline is dramatically slowed). Similar GBR 12909-induced dopamine uptake changes were observed in electrically-evoked dopamine efflux (Budygin et al., 1999; Budygin et al., 2000). Norepinephrine is the only other analyte known to closely approximate the chemical signature of dopamine in the NAc. However, the fact that the pinch-evoked catecholamine signal is markedly prolonged by the dopamine transporter blockade pharmacologically verifies the identity of dopamine (norepinephrine efflux is insensitive to dopamine uptake inhibition). Moreover, a recent study from our laboratory showed that norepinephrine signaling is restricted to caudal portions of the NAc shell but not rostral (Park et al., 2010) which was targeted in the present study. Therefore, the possibility that norepinephrine contributes to the measured signals in the tested brain regions in response to painful stimuli is unlikely in the current study.

\section{DISCUSSION}

Our data clearly demonstrate that a tail pinch triggers an increase in striatal dopamine release. This increase is subregion-dependent and time locked with the stimulus in the dorsal striatum and NAc core. In contrast, there was a substantial delay in the initiation of dopamine release in the NAc shell in response to a tail pinch. Specifically, NAc shell dopamine release was triggered at the offset of the tail pinch. This is the first demonstration of real-time dopamine release changes within striatum in response to brief $(3 \mathrm{~s})$ aversive episodes.

Different neurochemical approaches have been used in an attempt to explore the effects of aversive and stressful stimuli on dopamine neurotransmission in rat brain (Marcangione et al.; Pei et al., 1990; Klitenick et al., 1996; Rouge-Pont et al., 1998; Di Chiara et al., 1999; Giorgi et al., 2003; Stevenson et al., 2003; Amato et al., 2011). Several microdialysis studies 
assessed striatal dopamine alterations in response to a tail pinch in freely moving animals (Pei et al., 1990; Klitenick et al., 1996; Rouge-Pont et al., 1998; Di Chiara et al., 1999; Giorgi et al., 2003; Amato et al., 2011). However, these studies applied a long lasting tail pinch (from 5 to $40 \mathrm{~min}$ ) and collected dialysate samples every 10-20 minutes thereafter. An exposure to acute stress caused by unexpected tail pinch induced continuous ( 20-60 min) changes in extracellular dopamine, including increases in the dorsal striatum, NAc core and NAc shell (Klitenick et al., 1996; Rouge-Pont et al., 1998; Giorgi et al., 2003; Amato et al., 2011) in some studies, while others demonstrated that dopamine levels did not change (Giorgi et al., 2003) or decreased (Di Chiara et al., 1999) in the NAc shell. Several factors may account for the contrasting results in the shell region, including the selected rat strains, and the intensity and duration of the tail pinch used by different groups. Importantly, these microdialysis studies evaluated stress-associated changes in tonic dopamine activity that were provoked by the protracted noxious stimuli. While microdialysis is a suitable technique to evaluate dopamine fluctuations on a time scale of minutes, for questions concerning phasic release in response to a brief (2-4 s) painful stimulus, such as a tail pinch, faster sampling techniques are required.

FSCV is a technique that allows measurements of brief (seconds) dopamine effluxes (phasic dopamine release), therefore it is possible to make real associations between a briefly applied stimulus and prompt dopamine changes (Phillips et al., 2003; Wightman et al., 2007; Owesson-White et al., 2008; Roitman et al., 2008). In sharp contrast to the extensive research on reward-associated activity, only a few studies have attempted to explore changes in phasic dopamine activity in NAc following an aversive stimulus using FSCV (Roitman et al., 2008; Anstrom et al., 2009). One of these studies revealed significant increases in subsecond dopamine transmission in the NAc core of rats under the aversive condition of social defeat stress, in which an animal is exposed to an aggressive resident (Anstrom et al., 2009). However, social defeat is a complex condition in which an animal detects and responds to multiple stimuli of various origins. Therefore, it is unclear whether this increase in dopamine was produced by aversive stimuli (onset versus offset) or an ancillary stimulus or behavior. A second study explored causality between stimuli with opposing valences and dopamine responses in the NAc shell using aversive and appetitive tastants (i.e. $4 \mathrm{~s}$ intra-oral infusions of quinine and sucrose, respectively). These data are consistent with the hypothesis that the direction of phasic dopamine activity encodes the valence of the stimuli in the NAc, in that the aversive taste produced a decrease in dopamine release while the appetitive taste induced an increase (Roitman et al., 2008). Although the two studies seem to contradict one another, taste aversion and social defeat undoubtedly engage different sensory mechanisms and neural processes. Furthermore, the social defeat study examined the NAc core while the taste aversion data were collected from the shell of the NAc, perhaps indicating regional differences within the NAc in processing anhedonic stimuli.

Pain, which is certainly an important component of a tail pinch, is a complicated sensation which produces a specific emotional reaction and also activates multiple mechanisms, some of which are aimed at blunting the unpleasantness of the stimulus (Leknes and Tracey, 2008). Moreover, even a brief pain episode can generate a mild form of stress and induce motor activation. These responses can also be associated with dopamine increases in striatal subregions (Budygin et al., 2000; Garris et al., 2003; Anstrom et al., 2009). To rule out emotional and motor responses in the triggering of dopamine release, the current study was performed on anesthetized rats. In fact, the responsiveness of single dopamine neurons to aversive stimuli in anesthetized rats has been well documented by electrophysiological studies (Ungless et al., 2004; Brischoux et al., 2009).

Our observation of instant increase in subsecond dopamine release observed in two striatal regions (dorsal striatum and NAc core) during a tail pinch may be an attempt of the reward 
circuit to dampen the noxious sensation, perhaps in a manner similar to endorphin release during pain. The notion that dopamine has a role in endogenous antinociception is not new (Wood, 2006). Indeed, analgesia induced by pleasurable stimuli, including sexual behavior (Gear et al., 1999), pleasant food (Reboucas et al., 2005) and even pleasurable music (Roy et al., 2008), has been reported and importantly most of these stimuli have been associated with increased subsecond dopamine release in the NAc. Since dopamine responses in the dorsal striatum and NAc core can be triggered by aversive states in the same fashion as rewarding stimuli, another intriguing speculation is that the phasic dopamine in these brain regions encodes saliency. This assumption is in line with the earlier proposed "switching" hypothesis which states that dopamine neurons are activated by all salient stimuli (Redgrave et al., 1999).

The demonstration of dopamine release in the NAc shell, which is the most prominent region implicated in the perception of reward, occurring at the offset but not during exposure to noxious stimuli may indicate that the termination of acute pain has a strong rewarding component. Our findings are consistent with a recent human imaging study which demonstrated that a painful (thermal) stimulus increased the fMRI BOLD signal in the ventral striatum both at the onset and in the falling phase of pain (Baliki et al., 2010). This imaging technique does not have the ability to distinguish the subregions of the NAc, and the pattern of activation likely reflects an efflux of dopamine first in the core and then the shell of the accumbens. Our findings of subregional differences in dopamine responses to noxious stimuli are also in line with recent electrophysiological results, which were obtained in anesthetized rats (Brischoux et al., 2009) and freely moving mice (Zweifel et al., 2011; Wang and Tsien, 2011). According to these data, some putative dopamine neurons in the VTA exhibit significant activation in response to a noxious stimulus or fearful experiences, while some dopamine cells exhibit suppression or no changes and offset-rebound excitation. Therefore, an increase in phasic dopamine activity in terminals should be expected at both the onset of an aversive stimulus as well as its termination. However, this point remains speculative, since it is still unclear how release from terminals, which is the measurement of our study, are linked with the neuronal populations recorded in electrophysiological studies. Further experiments, which will combine simultaneously voltammetric and electrophysiological recordings in the same animal, are required to address this issue. Nevertheless, our neurochemical results reveal the differential subsecond dopamine response to aversive stimulation in two accumbal subregions, core and shell, highlighting the critical role of dopamine transmission in the shell for encoding the valence of stimuli. Taken together, our data also suggest the existence of some overlap in the neurochemistry of pain and pleasure processing in the striatum. Therefore, the increase in accumbal dopamine release in response to aversive stimuli is not contradictory to the accepted central role of fast dopamine signaling in reward processing. Moreover, our neurochemical findings may further bridge controversial hypotheses of information coding through dopamine signaling, which were originally based on electrophysiological results ( Schultz, 1998; Redgrave et al., 1999; Montague et al., 2004a; Ungless, 2004; Ungless et al., 2004; Redgrave et al., 2008; Brischoux et al., 2009; Lammel et al., 2011).

\section{Acknowledgments}

This work was supported by WFU Cross-Campus Collaborative Fund Award (EAB and KDB) and NIH grants DA021634 (EAB), DA024763 (CEB) and DA109000 (RMW).

\section{Abbreviations}

VTA ventral tegmental area 

NAc
nucleus accumbens
FSCV
fast-scan-cyclic voltammetry

\section{References}

Amato D, Natesan S, Yavich L, Kapur S, Muller CP. Dynamic regulation of dopamine and serotonin responses to salient stimuli during chronic haloperidol treatment. Int J Neuropsychopharmacol. 2011:1-13.

Anstrom KK, Miczek KA, Budygin EA. Increased phasic dopamine signaling in the mesolimbic pathway during social defeat in rats. Neuroscience. 2009; 161:3-12. [PubMed: 19298844]

Baliki MN, Geha PY, Fields HL, Apkarian AV. Predicting value of pain and analgesia: nucleus accumbens response to noxious stimuli changes in the presence of chronic pain. Neuron. 2010; 66:149-160. [PubMed: 20399736]

Brischoux F, Chakraborty S, Brierley DI, Ungless MA. Phasic excitation of dopamine neurons in ventral VTA by noxious stimuli. Proc Natl Acad Sci U S A. 2009; 106:4894-4899. [PubMed: 19261850]

Budygin EA, Kilpatrick MR, Gainetdinov RR, Wightman RM. Correlation between behavior and extracellular dopamine levels in rat striatum: comparison of microdialysis and fast-scan cyclic voltammetry. Neurosci Lett. 2000; 281:9-12. [PubMed: 10686403]

Budygin EA, Gainetdinov RR, Kilpatrick MR, Rayevsky KS, Mannisto PT, Wightman RM. Effect of tolcapone, a catechol-O-methyltransferase inhibitor, on striatal dopaminergic transmission during blockade of dopamine uptake. Eur J Pharmacol. 1999; 370:125-131. [PubMed: 10323260]

Day JJ, Roitman MF, Wightman RM, Carelli RM. Associative learning mediates dynamic shifts in dopamine signaling in the nucleus accumbens. Nat Neurosci. 2007; 10:1020-1028. [PubMed: 17603481]

Di Chiara G, Loddo P, Tanda G. Reciprocal changes in prefrontal and limbic dopamine responsiveness to aversive and rewarding stimuli after chronic mild stress: implications for the psychobiology of depression. Biol Psychiatry. 1999; 46:1624-1633. [PubMed: 10624543]

Garris PA, Budygin EA, Phillips PE, Venton BJ, Robinson DL, Bergstrom BP, Rebec GV, Wightman RM. A role for presynaptic mechanisms in the actions of nomifensine and haloperidol. Neuroscience. 2003; 118:819-829. [PubMed: 12710989]

Gear RW, Aley KO, Levine JD. Pain-induced analgesia mediated by mesolimbic reward circuits. J Neurosci. 1999; 19:7175-7181. [PubMed: 10436070]

Giorgi O, Lecca D, Piras G, Driscoll P, Corda MG. Dissociation between mesocortical dopamine release and fear-related behaviours in two psychogenetically selected lines of rats that differ in coping strategies to aversive conditions. Eur J Neurosci. 2003; 17:2716-2726. [PubMed: 12823478]

Klitenick MA, Taber MT, Fibiger HC. Effects of chronic haloperidol on stress- and stimulationinduced increases in dopamine release: tests of the depolarization block hypothesis. Neuropsychopharmacology. 1996; 15:424-428. [PubMed: 8887997]

Lammel S, Hetzel A, Hackel O, Jones I, Liss B, Roeper J. Unique properties of mesoprefrontal neurons within a dual mesocorticolimbic dopamine system. Neuron. 2008; 57:760-773. [PubMed: 18341995]

Lammel S, Ion DI, Roeper J, Malenka RC. Projection-specific modulation of dopamine neuron synapses by aversive and rewarding stimuli. Neuron. 2011; 70:855-862. [PubMed: 21658580]

Leknes S, Tracey I. A common neurobiology for pain and pleasure. Nat Rev Neurosci. 2008; 9:314320. [PubMed: 18354400]

Marcangione C, Constantin A, Clarke PB. Lack of effect of dopaminergic denervation on caudateputamen hyperthermia or hypothermia induced by drugs and mild stressors. Pharmacol Biochem Behav. 96:32-39. [PubMed: 20398690]

Matsumoto M, Hikosaka O. Two types of dopamine neuron distinctly convey positive and negative motivational signals. Nature. 2009; 459:837-841. [PubMed: 19448610] 
Montague PR, Hyman SE, Cohen JD. Computational roles for dopamine in behavioural control. Nature. 2004a; 431:760-767. [PubMed: 15483596]

Montague PR, McClure SM, Baldwin PR, Phillips PE, Budygin EA, Stuber GD, Kilpatrick MR, Wightman RM. Dynamic gain control of dopamine delivery in freely moving animals. J Neurosci. 2004b; 24:1754-1759. [PubMed: 14973252]

Owesson-White CA, Cheer JF, Beyene M, Carelli RM, Wightman RM. Dynamic changes in accumbens dopamine correlate with learning during intracranial self-stimulation. Proc Natl Acad Sci U S A. 2008; 105:11957-11962. [PubMed: 18689678]

Park J, Aragona BJ, Kile BM, Carelli RM, Wightman RM. In vivo voltammetric monitoring of catecholamine release in subterritories of the nucleus accumbens shell. Neuroscience. 2010; 169:132-142. [PubMed: 20451589]

Pei Q, Zetterstrom T, Fillenz M. Tail pinch-induced changes in the turnover and release of dopamine and 5-hydroxytryptamine in different brain regions of the rat. Neuroscience. 1990; 35:133-138. [PubMed: 1694282]

Phillips PE, Stuber GD, Heien ML, Wightman RM, Carelli RM. Subsecond dopamine release promotes cocaine seeking. Nature. 2003; 422:614-618. [PubMed: 12687000]

Reboucas EC, Segato EN, Kishi R, Freitas RL, Savoldi M, Morato S, Coimbra NC. Effect of the blockade of mu1-opioid and 5HT2A-serotonergic/alpha1-noradrenergic receptors on sweetsubstance-induced analgesia. Psychopharmacology (Berl). 2005; 179:349-355. [PubMed: 15821952]

Redgrave P, Prescott TJ, Gurney K. Is the short-latency dopamine response too short to signal reward error? Trends Neurosci. 1999; 22:146-151. [PubMed: 10203849]

Redgrave P, Gurney K, Reynolds J. What is reinforced by phasic dopamine signals? Brain Res Rev. 2008; 58:322-339. [PubMed: 18055018]

Roitman MF, Wheeler RA, Wightman RM, Carelli RM. Real-time chemical responses in the nucleus accumbens differentiate rewarding and aversive stimuli. Nat Neurosci. 2008; 11:1376-1377. [PubMed: 18978779]

Rouge-Pont F, Deroche V, Le Moal M, Piazza PV. Individual differences in stress-induced dopamine release in the nucleus accumbens are influenced by corticosterone. Eur J Neurosci. 1998; 10:39033907. [PubMed: 9875367]

Roy M, Peretz I, Rainville P. Emotional valence contributes to music-induced analgesia. Pain. 2008; 134:140-147. [PubMed: 17532141]

Schultz W. Predictive reward signal of dopamine neurons. J Neurophysiol. 1998; 80:1-27. [PubMed: 9658025]

Stevenson CW, Sullivan RM, Gratton A. Effects of basolateral amygdala dopamine depletion on the nucleus accumbens and medial prefrontal cortical dopamine responses to stress. Neuroscience. 2003; 116:285-293. [PubMed: 12535960]

Ungless MA. Dopamine: the salient issue. Trends Neurosci. 2004; 27:702-706. [PubMed: 15541509]

Ungless MA, Magill PJ, Bolam JP. Uniform inhibition of dopamine neurons in the ventral tegmental area by aversive stimuli. Science. 2004; 303:2040-2042. [PubMed: 15044807]

Wang DV, Tsien JZ. Convergent Processing of Both Positive and Negative Motivational Signals by the VTA Dopamine Neuronal Populations. PLoS One. 2011; 6:e17047. [PubMed: 21347237]

Wightman RM, Heien ML, Wassum KM, Sombers LA, Aragona BJ, Khan AS, Ariansen JL, Cheer JF, Phillips PE, Carelli RM. Dopamine release is heterogeneous within microenvironments of the rat nucleus accumbens. Eur J Neurosci. 2007; 26:2046-2054. [PubMed: 17868375]

Wood PB. Mesolimbic dopaminergic mechanisms and pain control. Pain. 2006; 120:230-234. [PubMed: 16427195]

Zweifel LS, Fadok JP, Argilli E, Garelick MG, Jones GL, Dickerson TM, Allen JM, Mizumori SJ, Bonci A, Palmiter RD. Activation of dopamine neurons is critical for aversive conditioning and prevention of generalized anxiety. Nat Neurosci. 2011 


\section{Highlights}

Voltammetry was used to assess real-time dopamine response to the tail pinch

Dopamine release was time locked to the stimulus in the dorsal striatum and NAc core

NAc shell dopamine release was triggered at the offset of the stimulus

Aversive stimulus differentially triggers subsecond dopamine in reward regions 


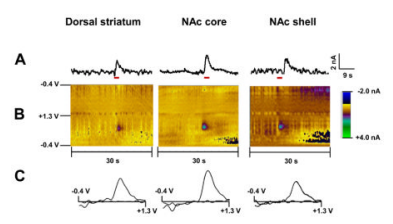

Fig. 1.

Dopamine changes detected by FSCV in the dorsal striatum, NAc core and NAc shell of anesthetized rats in response to tail pinch. (A) Representative concentration-time plots of stimulus (red line) evoked dopamine release measured in rat brain in real time. (B) Standard two dimensional color plots which topographically depict the voltammetric data with time on the $\mathrm{x}$-axis, applied scan potential on the $\mathrm{y}$-axis and background-subtracted faradaic current shown in the z-axis in pseudo-color. (C) Representative background-subtracted voltammograms obtained at the end of the stimulus showing characteristic oxidation and reduction peak potentials $(\sim+0.6 \mathrm{~V}$ and $\sim-0.2 \mathrm{~V}$, respectively) that identify dopamine. 


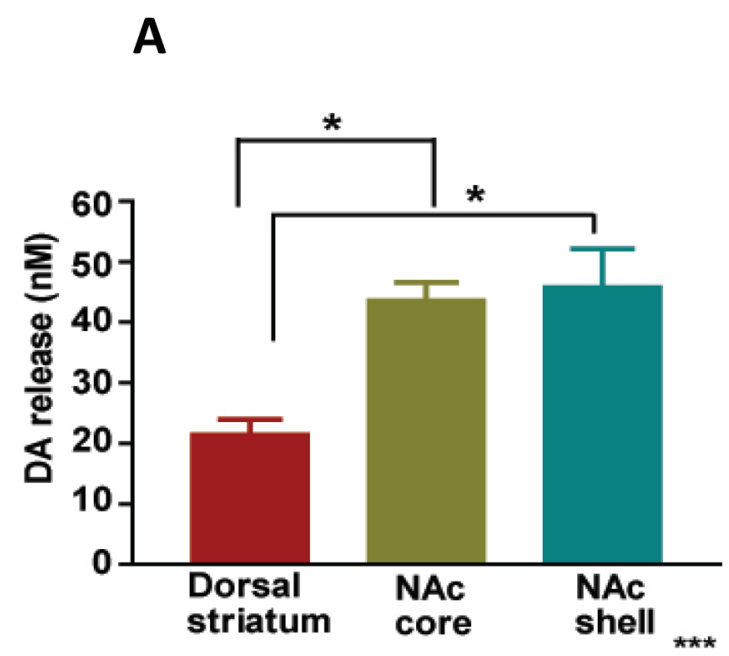

B
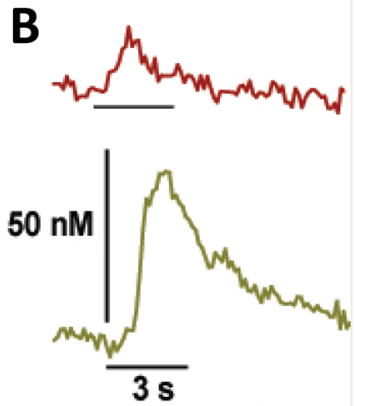

Delay (s) $\quad 0.20 \pm 0.08 \quad 0.28 \pm 0.15 \quad 2.9 \pm 0.34$

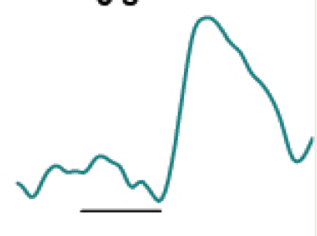

Fig. 2.

Extracellular dopamine changes detected in the dorsal striatum, NAc core and shell of anesthetized rats in response to tail pinch. (A) Maximal dopamine concentrations observed after tail pinch. The time between detected dopamine release and onset of the tail pinch in each region is also presented. Data are means \pm SEM of 6 rats per group. (B) Representative dopamine efflux detected in the dorsal striatum (upper), NAc core (middle) and shell (bottom) from individual animals. The black bar denotes the application of the tail pinch. 


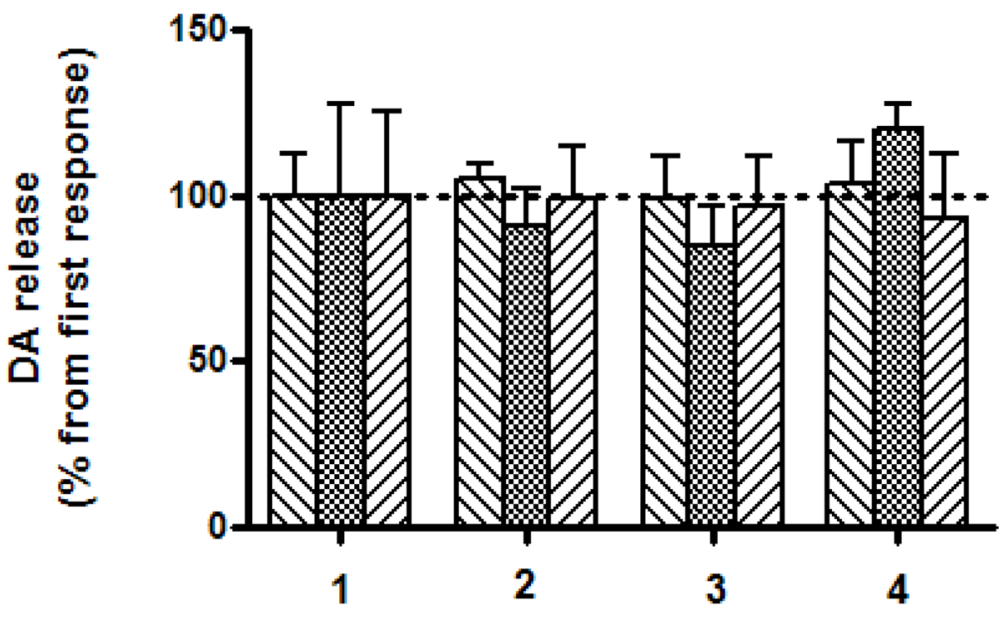

Pinch number

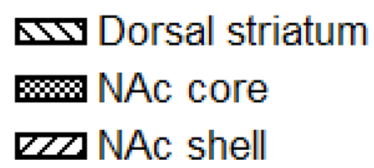

Fig. 3.

Effects of repetitive tail pinch administration on dopamine release in striatal subregions. Data are means \pm S.E.M. of five rats per group, expressed as the percent of dopamine response to the first tail pinch. Pinches were performed with 2-3 minutes intervals. 


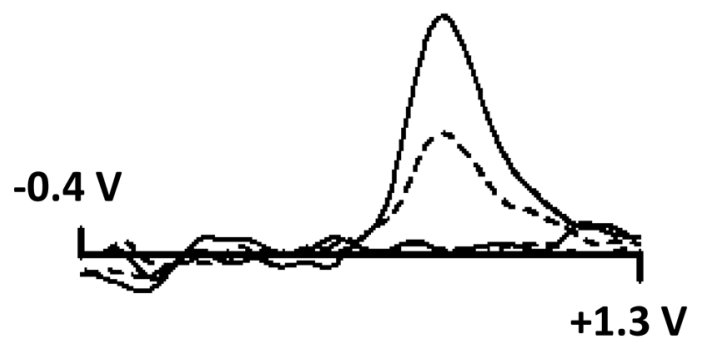

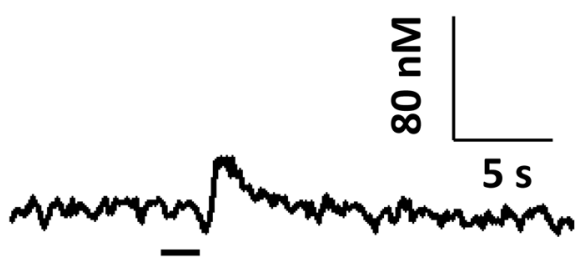

Predrug

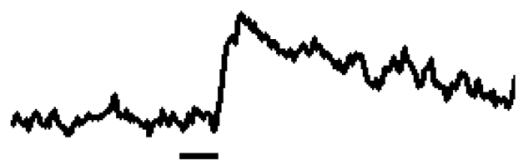

GBR 12909

Fig. 4.

Pharmacological confirmation of pinch-evoked dopamine signal in the NAc shell. Upper panel: Representative background-subtracted voltammograms recorded at peak response before (dotted line) and after administration of GBR 12909 (15 mg/kg, i.p.) (solid line). Lower panel: A marked decrease in the reuptake of catecholamine after dopamine uptake inhibition induced by GBR 12909 in comparison with predrug signal confirms that the detected substance is dopamine. The bar denotes the duration of the tail pinch. 


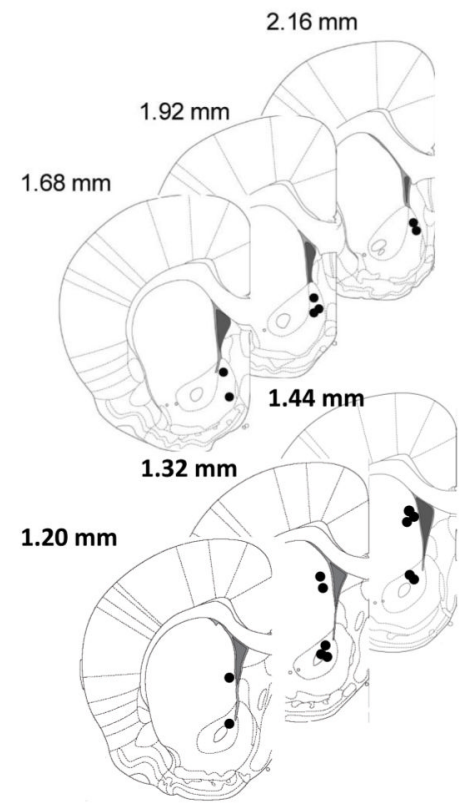

Fig. 5.

Anatomical distribution of carbon fiber electrode placements in the NAc shell (upper panel) and NAc core and dorsal striatum (lower panel) for all subjects. Numbers to the right indicate anteroposterior coordinates to bregma. 